\title{
Short-Term Adolescent Nicotine Exposure has Immediate and Persistent Effects on Cholinergic Systems: Critical Periods, Patterns of Exposure, Dose Thresholds
}

\author{
Yael Abreu-Villaça',2, Frederic J Seidler', Dan Qiao', Charlotte A Tate', Mandy M Cousins', Indira Thillai' \\ and Theodore A Slotkin*, I \\ 'Department of Pharmacology and Cancer Biology, Duke University Medical Center, Durham, NC, USA; 'Faculdade de Ciências Médicas, \\ Fundação Educacional Serra dos Órgãos (FESO), Teresópolis, Rio de Janeiro, Brazil
}

\begin{abstract}
In adolescents, the symptoms of nicotine dependence can appear well before the onset of habitual smoking. We investigated short-term nicotine exposure in adolescent rats for corresponding cholinergic alterations. Beginning on postnatal day 30, rats were given a I-week regimen of nicotine infusions or twice-daily injections, at doses $(0.6,2$, and $6 \mathrm{mg} / \mathrm{kg} / \mathrm{day})$ set to achieve plasma levels found in occasional to regular smokers. In the cerebral cortex, midbrain, and hippocampus, we assessed nicotinic cholinergic receptor (nAChR) binding, choline acetyltransferase (ChAT) activity, a constitutive marker for cholinergic nerve terminals, and $\left.{ }^{3} \mathrm{H}\right]$ hemicholinium-3 (HC-3) binding to the high-affinity choline transporter, which responds to cholinergic synaptic stimulation. nAChR upregulation was observed with either administration route, even at the lowest dose; in the hippocampus, increases could be detected with as little as 2 days' treatment at $0.6 \mathrm{mg} / \mathrm{kg} / \mathrm{day}$. In the midbrain, upregulation was still significant even I month post-treatment. Adolescent nicotine treatment also produced lasting decrements in HC-3 binding that were separable from effects on ChAT, suggesting cholinergic synaptic impairment. Again, these effects were obtained at the lowest dose and remained significant I month post-treatment. Our results indicate that in adolescence, even a brief period of continuous or intermittent nicotine exposure, elicits lasting alterations in cholinergic systems in brain regions associated with nicotine dependence. As the effects are detected at exposures that produce plasma concentrations as little as one-tenth of those in regular smokers, the exquisite sensitivity of the adolescent brain to nicotine may contribute to the onset of nicotine dependence even in occasional smokers.

Neuropsychopharmacology (2003) 28, 1935-1949, advance online publication, 4 June 2003; doi: I 0. I038/sj.npp. 1300221
\end{abstract}

Keywords: adolescence; choline acetyltransferase; cholinergic systems; hemicholinium-3 binding; nicotine; nicotinic cholinergic receptors

\section{INTRODUCTION}

Adolescence is associated with increases in novelty-seeking and risk-taking behaviors that assist in acquiring adult skills (Adriani et al, 2002; Spear, 2000), but at the same time contribute to experimentation with tobacco, alcohol, and illicit drugs (Spear, 2000). In recent years, nearly one-third of US high school students reported smoking cigarettes and about three thousand teenagers begin smoking every day (Centers for Disease Control and Prevention, 1998, 2000; National Institute on Drug Abuse, 1998). Of these, threequarters become daily smokers by the age of 20 (National

*Correspondence: Dr TA Slotkin, Box 3813 DUMC, Duke University Medical Center, Durham, NC 27710, USA, Tel: + I 919 68I 8015, Fax: + | 9196848197 , E-mail: t.slotkin@duke.edu

Received 27 January 2003; accepted 18 March 2003

Online publication: 22 April 2003 at http://www.acnp.org/citations/ Npp04220035/default.pdf
Institute on Drug Abuse, 1998; Nelson et al, 1995), comprising a cohort for whom smoking will be a long-term addiction (Pierce and Gilpin, 1996), with high daily consumption and a low probability of quitting (Chen and Millar, 1998). Accordingly, the number of deaths attributable to tobacco is expected to more than double worldwide by 2020 (Murray and Lopez, 1997).

Classically, the onset of nicotine dependence is considered to be a slow, sequential process requiring prolonged, daily smoking (DiFranza et al, 2000; Jackson, 1998; Lamkin and Houston, 1998; Leventhal and Cleary, 1980). However, recent studies indicate that subsets of adolescent smokers exhibit symptoms of nicotine dependence before the onset of daily smoking, often with only a few days of occasional tobacco use (DiFranza et al, 2000, 2002a, b; O'Loughlin et al, 2002). This suggests that the adolescent brain is inherently more susceptible to nicotine dependence, in keeping with the idea that responses to psychoactive substances are innately different during this developmental period (Cirulli 
and Laviola, 2000; Markwiese et al, 1998; Spear, 2000; Spear and Brake, 1983). In spite of these facts, only recently has basic research focused on the biological substrates that may underlie the susceptibility of the adolescent brain to nicotine dependence (Slotkin, 2002). It is well established that nicotine exposure during prenatal development induces cognitive and behavioral deficits that reflect deleterious actions of nicotine that alter cell proliferation and differentiation, synaptic maturation, and cell signaling (Levin and Slotkin, 1998; Slotkin, 1992, 1998, 1999). Brain development continues into adolescence, specifically encompassing neuroproliferation, apoptosis, and synaptic rearrangement (Bayer, 1983; Bayer et al, 1982; Huttenlocher, 1990). More specifically, the maturation of central cholinergic systems involved in learning, memory, and psychostimulant responses, is consolidated during the periadolescent period (Matthews et al, 1974; Nadler et al, 1974; Zahalka et al, 1993). We recently developed a rat model of adolescent nicotine exposure that produces plasma nicotine levels comparable to those in regular smokers $(25 \mathrm{ng} / \mathrm{ml})$ (Slotkin, 2002). The salient features of this model include more profound and persistent upregulation of nicotinic acetylcholine receptors (nAChRs) as compared to adults, as well as prolonged suppression of cholinergic activity, and desensitization of nAChRs after nicotine withdrawal (Trauth et al, 1999, 2000a, 2001). These effects are accompanied by unique patterns of behavioral alterations that distinguish the effects of adolescent nicotine administration and withdrawal from those seen in adults (Levin, 1999; Trauth et al, 2000c); the lasting desensitization of cholinergic inputs to monoaminergic systems (Trauth et al, 2001) likely contributes to long-term loss of psychostimulant reward responses (Kelley and Middaugh, 1999), as well as persistent changes in EEG and locomotor activity that have been characterized as a uniquely adolescent 'nicotine abstinence syndrome' (Slawecki and Ehlers, 2002).

Recent findings indicate that the nearly immediate loss of autonomy over cigarette smoking in adolescents (DiFranza et $\mathrm{al}, 2000,2002 \mathrm{a}, \mathrm{b})$ is paralleled in the rodent by rapid sensitization to nicotine's behavioral effects, centered around early adolescence (Adriani et al, 2002; Faraday et al, 2001). The current study was undertaken to identify the biological components that render the adolescent brain especially susceptible to nicotine, focusing on a specific set of questions. First, how long does the exposure need to be in order to elicit nAChR upregulation or to produce persistent reductions in cholinergic activity after nicotine withdrawal? Second, can these effects be elicited at plasma nicotine levels lower than those found in regular, active smokers, down to the exposures typical of occasional smoking or exposure to environmental tobacco smoke (ETS)? Third, does the pattern of exposure matter? Regular smokers tend to maintain a constant blood level of nicotine during the daytime, whereas occasional users and those subjected to workplace ETS show episodic exposures. This issue is particularly important in trying to understand biological substrates that might underlie the loss of autonomy in adolescent humans who smoke only a few cigarettes (DiFranza et al, 2000, 2002a, b). Fourth, what is the role of secondary effects of nicotine or tobacco smoke mediated through weight loss and anorexia, or through the episodic hypoxic/ischemic burden associated with smoking (Bush et al, 2000; Slotkin, 1992)? Fifth, to what extent do the effects of adolescent nicotine treatment on cholinergic systems reflect underlying neurotoxicity?

To answer these questions, we used the adolescent rat model to examine the dose-response and time-response relations for effects of nicotine involving exposures of only 1 week's duration (and in one situation, as little as 2 days), with studies carried out during nicotine exposure and for up to 1 month after the initiation of withdrawal. To evaluate the role of different patterns of nicotine exposure (continuous $v s$ intermittent), we contrasted two different routes of administration: infusions via implanted osmotic minipumps and twice-daily subcutaneous injections. Nicotine was administered at three different doses $(0.6,2$, and $6 \mathrm{mg} /$ $\mathrm{kg}$ /day) that, with the infusion model, elicit plasma levels ranging from as little as $2.5-25 \mathrm{ng} / \mathrm{ml}$ (Lichtensteiger et al, 1988; Trauth et al, 2000b). In light of the unique behavioral sensitization seen in early adolescence (Adriani et al, 2002), we concentrated on exposure beginning on postnatal day (PN) 30, which, on the basis of brain development, onset of puberty, and patterns of drug reactivity, represents the early adolescent stage in the rat (Spear, 2000). Three cholinergic biomarkers were considered. For evaluation of effects on nAChRs, we utilized $\left[{ }^{3} \mathrm{H}\right]$ cytisine, a ligand that binds selectively to the $\alpha 4 \beta 2 \mathrm{nAChR}$, the predominant subtype in mammalian brain; this receptor subtype is robustly upregulated by nicotine administration (Flores et al, 1992; Happe et al, 1994; Whiting and Lindstrom, 1987, 1988), and shows preferential upregulation in the adolescent (Trauth et al, 1999). We also assessed choline acetyltransferase (ChAT) activity and the binding of $\left[{ }^{3} \mathrm{H}\right]$ hemicholinium-3 (HC-3) to the high-affinity presynaptic choline transporter. ChAT, the enzyme responsible for acetylcholine biosynthesis, is a constitutive marker for cholinergic nerve terminals and serves as an archetypal measure of cholinergic innervation, but its activity does not respond to changes in impulse flow. Accordingly, ChAT increases during cholinergic synaptogenesis but does not change in response to stimuli that alter cholinergic neuronal activity (Aubert et al, 1996; Happe and Murrin, 1992; Navarro et al, 1989; Slotkin et al, 1990; Zahalka et al, 1992, 1993). In contrast, high-affinity choline uptake, as assessed with the binding of HC-3 to the presynaptic high-affinity choline transporter, is responsive to neuronal activity (Klemm and Kuhar, 1979; Simon et al, 1976), and the comparative changes in ChAT and HC-3 binding or transporter function permit distinction between effects on synaptic outgrowth as distinct from synaptic activity (Aubert et al, 1996; Happe and Murrin, 1992; Navarro et al, 1989; Slotkin et al, 1990; Zahalka et al, 1992, 1993). Both ChAT and HC-3 binding have been used previously to characterize the differences between adolescent and adult responses to nicotine (Slotkin, 2002; Trauth et al, 2000a).

\section{MATERIALS AND METHODS}

\section{Animals}

All the studies were carried out with the approval of the Duke University Institutional Animal Care and Use Committee, in accordance with the declaration of Helsinki 
and the Guide for the Care and Use of Laboratory Animals as adopted and promulgated by the National Institutes of Health. Sprague-Dawley rats were shipped by a climatecontrolled truck (total transit time less that $12 \mathrm{~h}$ ), housed individually, and allowed free access to food and water.

\section{Nicotine Infusions}

For minipump infusions, on PN30, each animal was anesthetized lightly with ether, a $3 \times 4 \mathrm{~cm}$ area on the back was shaved and an incision made to permit s.c. insertion of osmotic minipumps (Alzet type 1007D). Pumps were prepared with nicotine bitartrate dissolved in bacteriostatic water, to deliver an initial dose rate of $0.6,2$, or $6 \mathrm{mg} / \mathrm{kg}$ of nicotine (calculated as free base) per day (Slotkin, 1998; Trauth et al, 1999, 2000b). The incision was closed with wound clips and the animals were permitted to recover in their home cages. The control animals were implanted with minipumps containing bacteriostatic water and sodium bitartrate equivalent to the highest nicotine bitartrate concentration. It should be noted that the pump, marketed as a 1-week infusion device, actually takes just under 8 days to be exhausted completely (information supplied by the manufacturer) and thus the nicotine infusion terminates during PN38. At the highest dose rate, this paradigm produces plasma nicotine levels similar to those in typical smokers, approximately $25 \mathrm{ng} / \mathrm{ml}$ (Trauth et al, 2000b). All the treatments were within the range over which the plasma nicotine level is linear with the dose rate (Lichtensteiger et al, 1988), so that at the intermediate and lower doses, concentrations were about 8 and $2.5 \mathrm{ng} / \mathrm{ml}$, respectively. The lowest concentration is thus ten times below that found in regular smokers, and well within the range of those with exposure to ETS (Eliopoulos et al, 1996; Fried et al, 1995; Jauniaux et al, 1999; Kohler et al, 1999; Ostrea et al, 1994).

Studies were conducted at three time points, one toward the end of the nicotine administration period (PN37), and the other two at 1 and 4 weeks after the end of nicotine exposure (PN45 and PN65, respectively). Animals were decapitated and the cerebral cortex, hippocampus, and midbrain were dissected (Trauth et al, 1999, 2000a, b, 2001), frozen in liquid nitrogen, and stored at $-45^{\circ} \mathrm{C}$ until assay. For some animals, we also removed the spleen for a separate study of lymphocyte mitogenic responses (Navarro et al, 2003).

\section{Nicotine Injections}

Experiments utilizing subcutaneous nicotine injections were designed to deliver the daily dose of nicotine in a bolus, thus providing a maximum pharmacokinetic contrast to the continuous infusion model. We administered nicotine for 7 days beginning on PN30, at the same total daily doses, but with the minimal number of daily injections. In preliminary experiments, we established that $3 \mathrm{mg} / \mathrm{kg}$ represented the maximum tolerated dose, thus requiring two injections each day, administered $12 \mathrm{~h}$ apart, so as to deliver the total dose of $6 \mathrm{mg} / \mathrm{kg} /$ day for the high-dose group; similarly, the lower dose groups received two daily injections of 1 or $0.3 \mathrm{mg} / \mathrm{kg}$, for total doses of 2 and $0.6 \mathrm{mg} / \mathrm{kg} /$ day, respectively. Control animals received injections of bacteriostatic water containing sodium bitartrate in a concentration equivalent to that of the highest dose of nicotine. For the first few injections, the animals receiving the lower doses of injected nicotine showed increased motor activity for about 5-10 min, followed by an equivalent period of depressed activity. The highest dose elicited rapid respiration and suppressed motor activity lasting 10-15 min, and some animals showed characteristics of systemic hypoxia, such as blanching of the skin and cyanosis (McFarland et al, 1991; Slotkin, 1992); of the 36 rats receiving high-dose nicotine injections, four animals (two males, two females) exhibited seizures and died. In the remainder, tolerance developed to all these effects by the second day. As the group receiving the highest dose of injected nicotine experienced systemic toxicity and corresponding weight loss, this group was also used to contrast the secondary toxic effects of nicotine with those mediated at lower doses of injected nicotine, or with nicotine infusions, both of which were devoid of overt systemic toxicity. Studies were conducted on PN37 (12 h after the last nicotine injection), PN45, and PN65, just as for the infusion regimens.

\section{Tissue Preparation}

Tissues were thawed and homogenized (Polytron, Brinkmann Instruments, Westbury, NY) in 20-40 volumes of icecold $50 \mathrm{mM}$ Tris $\mathrm{HCl}(\mathrm{pH} 7.4)$ and aliquots were withdrawn for measurements of ChAT activity (Lau et al, 1988) and total protein (Smith et al, 1985). To prepare the cell membrane fraction, the homogenates were sedimented at $40000 \mathrm{~g}$ for $10 \mathrm{~min}$ and the supernatant solution was discarded. The membrane pellet was resuspended (Polytron) in the original volume of buffer, resedimented, and the resultant pellet was resuspended in the same buffer using a smooth glass homogenizer fitted with a Teflon pestle. Aliquots of this resuspension were withdrawn for measurements of $\left[{ }^{3} \mathrm{H}\right]$ cytisine and $\left[{ }^{3} \mathrm{H}\right] \mathrm{HC}-3$ binding, and for membrane protein.

\section{Assays}

For ChAT activity, assays contained $30 \mu \mathrm{l}$ of diluted homogenate (corresponding to $125 \mu \mathrm{g}$ of original tissue weight) in a total volume of $60 \mu \mathrm{l}$ with final concentrations of $60 \mathrm{mM}$ sodium phosphate (pH 7.9), $200 \mathrm{mM} \mathrm{NaCl}, 20 \mathrm{mM}$ choline chloride, $17 \mathrm{mM} \mathrm{MgCl}_{2}, 1 \mathrm{mM}$ EDTA, $0.2 \%$ Triton $\mathrm{X}-100,0.12 \mathrm{mM}$ physostigmine, $0.6 \mathrm{mg} / \mathrm{ml}$ bovine serum albumin, and $50 \mu \mathrm{M}\left[{ }^{14} \mathrm{C}\right]$ acetyl-coenzyme A. Blanks contained homogenization buffer instead of the tissue homogenate. Triplicate samples from each homogenate were preincubated for $15 \mathrm{~min}$ on ice, transferred to a $37^{\circ} \mathrm{C}$ water bath for $30 \mathrm{~min}$, and the reaction terminated by placing the samples on ice. Labeled acetylcholine was then extracted, counted and the activity determined relative to tissue protein. Preliminary determinations established that enzyme activity was linear with time and tissue concentration under these conditions.

$\left[{ }^{3} \mathrm{H}\right]$ Cytisine binding to nAChRs was assessed in quadruplicate aliquots of the membrane suspension, corresponding to $5 \mathrm{mg}$ of original wet weight of tissue (two aliquots for total binding and two for nonspecific binding). Each assay contained a final concentration of $1 \mathrm{nM}\left[{ }^{3} \mathrm{H}\right]$ cytisine in a total volume of $250 \mu \mathrm{l}$ of $120 \mathrm{mM} \mathrm{NaCl}, 5 \mathrm{mM} \mathrm{KCl}, 2.5 \mathrm{mM}$ 
$\mathrm{CaCl}_{2}, 1 \mathrm{mM} \mathrm{MgCl}_{2}$, and $50 \mathrm{mM}$ Tris $\mathrm{HCl}$ (pH 7.4). Incubations were conducted for $75 \mathrm{~min}$ at $4{ }^{\circ} \mathrm{C}$, after which $3 \mathrm{ml}$ of ice-cold buffer were added and the membranes trapped by filtration on glass fiber filters. Labeled membranes were washed three times with $4 \mathrm{ml}$ of buffer and the filters were counted by liquid scintillation spectrometry. Nonspecific binding was assessed by displacement with $20 \mu \mathrm{M}$ nicotine, and was about $10 \%$ of the total binding in the cerebral cortex and midbrain, and about $20 \%$ in the hippocampus. Values were then calculated as specific binding per $\mathrm{mg}$ of membrane protein. The selection of a single concentration of radioligand for the receptor analysis enables the detection of changes in binding, but does not permit distinction of whether the effects are exerted on receptor affinity $\left(K_{\mathrm{d}}\right)$ or capacity $\left(B_{\max }\right)$. This strategy was necessitated by tissue and technical limitations implicit in the requirement to conduct over 500 assays simultaneously in each individual experiment, entailing every sample for a given age point, region, and route of administration, comprising preparations from 48 animals (six males and six females from each of four treatment groups): triplicate samples of ChAT, quadruplicates for $\left[{ }^{3} \mathrm{H}\right]$ cytisine binding (two each for total and nonspecific binding), and quadruplicates for $\left[{ }^{3} \mathrm{H}\right] \mathrm{HC}-3$ binding (two total, two nonspecific). The overall study thus involved nearly 10000 assays. Nevertheless, it should be noted that, in earlier work, we demonstrated that the upregulation of nAChRs caused by adolescent nicotine represents an increase in the number of receptors and not a change in receptor affinity (Trauth et al, 1999).

For measurements of $\left[{ }^{3} \mathrm{H}\right] \mathrm{HC}-3$ binding, aliquots of the same membrane preparation, corresponding to $10 \mathrm{mg}$ of original tissue weight, were incubated in $10 \mathrm{mM}$ sodiumpotassium phosphate buffer $(\mathrm{pH} 7.4)$ and $150 \mathrm{mM} \mathrm{NaCl}$, for $10 \mathrm{~min}$ at $20^{\circ} \mathrm{C}$, using a ligand concentration of $2 \mathrm{nM}$ $\left[{ }^{3} \mathrm{H}\right] \mathrm{HC}-3$ (Vickroy et al, 1984). Membranes were trapped and washed as already described, except that the filters were presoaked for $30 \mathrm{~min}$ in a buffer containing $0.1 \%$ polyethyleneimine. The nonspecific component was defined as binding in the presence of an excess concentration $(10 \mu \mathrm{M})$ of unlabeled $\mathrm{HC}-3$ and again, specific binding was expressed relative to membrane protein. Previous work has shown that developmental changes in HC-3 binding reflect almost exclusively a change in the total concentration of transporter sites (Zahalka et al, 1993); however, the interpretation of results of the present study, which relate to HC-3 binding as an index of synaptic activity (Cheney et al, 1989; Jope, 1979; Murrin, 1980; Navarro et al, 1989; Shelton et al, 1979; Simon et al, 1976; Zahalka et al, 1992, 1993), does not depend upon whether the change is specific to concentration or affinity.

\section{Study Design and Data Analysis}

The study was conducted in two separate cohorts of animals, one for the infusion regimen and one for the injection regimen, with each cohort consisting of 36 animals. Six males and six females were used for each of the four treatment groups and for each of the three age points; the only exception was the group receiving the highest dose of injected nicotine, where five animals for each sex were used at PN45 and PN65. Statistical comparisons of the effects of nicotine were conducted solely on the appropriately matched control group (ie infusion or injection).

Data are presented as means and standard errors. To facilitate comparison across the different measurements, the effects of nicotine were compiled as the percent change from control values, but statistical evaluations involved only the original data; for reference, control values for all variables (combined across the two cohorts) appear in Table 1. The effects of nicotine were first evaluated with a global analysis of variance (ANOVA) incorporating all the variables and measures in a single test, and utilizing logtransformation because of the heterogeneous variance among the different measures: treatment group, route of administration, brain region, age, sex, and the three neurochemical variables (nAChR binding, ChAT, and HC3 binding). The three assays were treated as repeated measures, since each was obtained from the same tissue homogenate. Since the initial test (see Results) found that treatment effects were dependent upon the type of

Table I Control Values for Weights and Cholinergic Biomarkers

\begin{tabular}{|c|c|c|c|c|c|c|c|}
\hline \multirow[b]{2}{*}{ Measure } & \multirow[b]{2}{*}{ Region } & \multicolumn{2}{|c|}{ PN37 } & \multicolumn{2}{|c|}{ PN45 } & \multicolumn{2}{|c|}{ PN65 } \\
\hline & & Male & Female & Male & Female & Male & Female \\
\hline Body weight (g) & & $189 \pm 3$ & $162 \pm 5^{*}$ & $275 \pm 7$ & $225 \pm 8^{*}$ & $431 \pm 9$ & $275 \pm 8^{*}$ \\
\hline \multirow[t]{3}{*}{ Region weight (mg) } & Midbrain & $266 \pm 4$ & $258 \pm 2$ & $284 \pm 4$ & $276 \pm 4$ & $295 \pm 7$ & $278 \pm 5$ \\
\hline & Cerebral cortex & $842 \pm 16$ & $794 \pm 14 *$ & $892 \pm 22$ & $836 \pm 14^{*}$ & $902 \pm 20$ & $850 \pm 14 *$ \\
\hline & Hippocampus & $109 \pm 2$ & $104 \pm 2^{*}$ & $117 \pm 5$ & $105 \pm 2$ & $118 \pm 2$ & $108 \pm 3^{*}$ \\
\hline \multirow[t]{3}{*}[{}^{3}\mathrm{H}]{ Cytisine binding (fmol/mg protein) } & Midbrain & $89 \pm 3$ & $88 \pm 4$ & $85 \pm 2$ & $83 \pm 2$ & $75 \pm 2$ & $78 \pm 2$ \\
\hline & Cerebral cortex & $63 \pm 2$ & $68 \pm 3$ & $64 \pm 3$ & $65 \pm 3$ & $56 \pm 2$ & $58 \pm 2$ \\
\hline & Hippocampus & $42 \pm 2$ & $46 \pm 3$ & $39 \pm 2$ & $37 \pm 3$ & $36 \pm 2$ & $36 \pm 1$ \\
\hline \multirow[t]{3}{*}{ ChAT (pmol/min/mg protein) } & Midbrain & $522 \pm 23$ & $537 \pm 23$ & $512 \pm 12$ & $522 \pm 13$ & $479 \pm 10$ & $531 \pm 21 *$ \\
\hline & Cerebral cortex & $595 \pm 15$ & $578 \pm 8$ & $546 \pm 9$ & $541 \pm 11$ & $549 \pm 14$ & $539 \pm 8$ \\
\hline & Hippocampus & $565 \pm 16$ & $580 \pm 16$ & $536 \pm 12$ & $597 \pm 1 \mid *$ & $582 \pm 19$ & $669 \pm 27 *$ \\
\hline \multirow[t]{3}{*}[{}^{3}\mathrm{H}]{$\mathrm{HC}-3$ binding (fmol/mg protein) } & Midbrain & $7.8 \pm 0.6$ & $8.5 \pm 0.9$ & $10.4 \pm 0.6$ & $10.4 \pm 0.5$ & $10.0 \pm 0.6$ & $9.5 \pm 0.7$ \\
\hline & Cerebral cortex & $9.6 \pm 0.5$ & $9.9 \pm 0.4$ & $10.7 \pm 0.7$ & $1 \mid .2 \pm 0.8$ & $11.8 \pm 0.5$ & $|3| \pm 0.6$. \\
\hline & Hippocampus & $13.2 \pm 0.9$ & $15.4 \pm 1.2$ & $13.9 \pm 1.1$ & $14.9 \pm 1.2$ & $16.9 \pm 0.6$ & $17.6 \pm 1.0$ \\
\hline
\end{tabular}

Values were combined across both cohorts of control groups (those receiving vehicle administration by infusion and by injection). However, statistical comparisons of the effects of nicotine were made only with the appropriately matched control cohort. The asterisks denote control values for which females differ significantly from males. 
measurement (interactions of treatment $\times$ measure, treatment $\times$ measure $\times$ other variables), the route of administration (interactions of treatment $\times$ route, treatment $\times$ route $\times$ other variables), and the specific brain region in which the measurement was made (interactions of treatment $\times$ region, treatment $\times$ region $\times$ other variables), the data were subdivided into the individual measurements, routes, and regions. Lower-order ANOVAs were then conducted, and where interactions of treatment with the remaining variables were still detected, comparisons for each individual values were carried out using Fisher's Protected Least Significant Difference. However, where treatment effects did not interact with other variables, only the main effect was interpreted. In cases where an interaction of treatment $\times$ sex remained detectable in the lower-order tests, separate analyses were carried out for males and females; otherwise, values were compiled for both sexes combined.

Effects of nicotine on weight variables were conducted similarly. For body weight, we used a four-factor ANOVA (treatment, route, age, and sex), and five factors (additional factor of region) for brain region weight, both with logtransformed values.

Significance was assumed at the level of $p<0.05$ for main effects. For interactions at $p<0.1$, we also examined whether lower-order main effects were detectable after subdivision of the interactive variables (Snedecor and Cochran, 1967).

\section{Materials}

Animals were purchased from Zivic Laboratories (Pittsburgh, PA) and osmotic minipumps from Durect Corp. (Cupertino, CA). Bacteriostatic water was obtained from Abbott Laboratories (N. Chicago, IL). Radioisotopically labeled compounds came from Perkin-Elmer Life Sciences (Boston, MA): [ ${ }^{14} \mathrm{C}$ ]acetyl-CoA (specific activity $44 \mathrm{mCi} /$ $\mathrm{mmol}$, diluted with unlabeled compound to $6.7 \mathrm{mCi} / \mathrm{mmol}$ ), $\left[{ }^{3} \mathrm{H}\right] \mathrm{HC}-3$ (specific activity $161 \mathrm{Ci} / \mathrm{mmol}$ ), and $\left[{ }^{3} \mathrm{H}\right]$ cytisine (specific activity, $32 \mathrm{Ci} / \mathrm{mmol}$ ). Sigma Chemical Co. (St Louis, MO) was the source for all other reagents.

\section{RESULTS}

\section{Effects on Body and Tissue Weights}

ANOVA across both routes of nicotine administration indicated an overall effect on body weight only in the group receiving the highest dose $(p<0.002$ for the main treatment effect; $p<0.0001$ for control $v s$ nicotine $6 \mathrm{mg} / \mathrm{kg} /$ day; other groups not significant $v s$ control). The effect of nicotine was interactive with the route of administration $(p<0.03)$, so body weights were re-evaluated after separation of the groups into the infusion and injection paradigms (Figure 1). In keeping with an earlier study (Trauth et al, 1999), nicotine infusions had little or no effect on body weights (not statistically significant). However, for injected nicotine, significant differences remained detectable; again, the reductions were confined to the group receiving the highest dose, amounting to approximately a $5-10 \%$ deficit throughout the test period. The deficits arose very early in the treatment period, as examination of body weights on PN32, after just 2 days of injections, indicated a significant $(p<0.002)$ deficit of the same magnitude (data not shown).

Nicotine-induced differences in body weight did not correlate with differences in brain region weights (Figure 1). Across all treatments, regions and ages, and both routes and sexes, we detected only an interaction of treatment $\times$ age $(p<0.04)$ and a marginal interaction of treatment $\times$ age $\times$ sex $\quad(p<0.09)$. These differences reflected inconsistent effects of small magnitude. After separation of the values by the more robust interactive term (age), we found significant, sex-dependent effects on PN37 (treatment $\times$ sex, $p<0.03$ ) and a main effect of nicotine on PN65 $(p<0.006)$. The effect on PN37 did not maintain statistical significance when the values were separated by sex. On PN65, the effect, a $4 \%$ increase over control values $(p<0.0007)$, was confined to the group receiving the lowest dose of nicotine $(0.6 \mathrm{mg} / \mathrm{kg} /$ day $)$.

\section{Overall Statistical Analysis of Cholinergic Biomarkers}

In order to reduce the likelihood of type 1 statistical errors, all the values obtained for the three neurochemical measures were first evaluated in a single multivariate ANOVA (Table 2), combining all contributing variables and all three measures. Across both routes of administration, we found significant interactions of treatment $\times$ measure, treatment $\times$ route of administration, and treatment $\times$ measure $\times$ brain region, indicating the need to separate the data according to the two different treatment regimens and the three individual brain regions. To ensure that interactions with measure and region were maintained for each route of administration, we repeated the global ANOVA for each route separately, and again found interactions of treatment $\times$ measure and treatment $\times$ measure $\times$ region. Nicotine treatment was also interactive with age and sex, so after subdividing the data by route, region and measure, we retained these variables in the analysis to see if treatment interactions remained detectable. Thus, despite the absence of significant deficits in brain region weights, there were robust differences in cholinergic biomarkers.

\section{Effects on $\left[{ }^{3} \mathrm{H}\right]$ Cytisine Binding}

Across all doses, ages, regions, both routes, and both sexes, adolescent nicotine treatment elicited a significant main effect $(p<0.0001)$ as well as interactions of treatment $\times$ route of administration $(p<0.07)$, treatment $\times$ age $(p<0.0001)$, treatment $\times$ route $\times$ age $(p<0.002)$, treatment $\times$ route $\times$ region $(p<0.02), \quad$ treatment $\times$ age $\times$ sex $(p<0.04)$, treatment $\times$ age $\times$ region $(p<0.1)$, treatment $\times$ sex $\times$ region $(p<0.002)$, treatment $\times$ route $\times$ age $\times$ region $(p<0.006)$, and treatment $\times$ route $\times$ sex $\times$ region $(p<0.0006)$. Accordingly, the data were subdivided into separate regions and routes of administration for further analysis.

Adolescents given nicotine infusions showed upregulation of nAChRs in all the three brain regions (Figure 2, lefthand panels). On PN37, during the period of nicotine administration, there was significant induction even at the lowest dose of nicotine ( $p<0.0004$ across all regions), rising to a $30-40 \%$ increase at the highest dose $(p<0.0001$ across all regions). In the midbrain, values declined to normal 
within 1 week after termination of the infusion but there was a secondary increase seen on PN65, 1 month after the end of nicotine exposure; the lack of effect on PN45 was statistically distinguishable from the delayed induction on
PN65 (treatment $\times$ age, $p<0.05$ ). In contrast to the effects in the midbrain, nAChR binding in the cerebral cortex and hippocampus remained significantly elevated on PN45 and returned to normal by PN65.
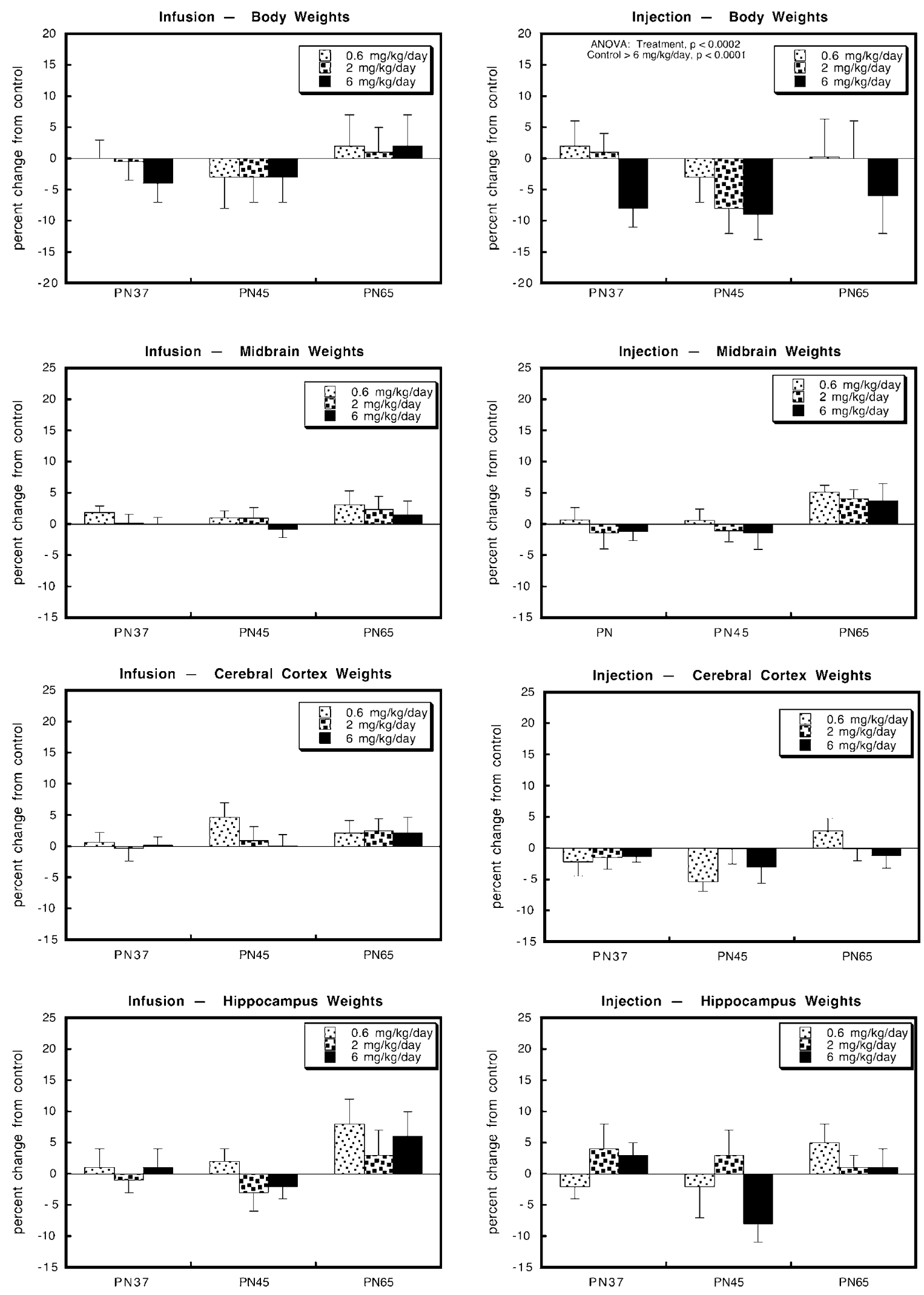
Table 2 Overall Analysis of Cholinergic Biomarkers

\begin{tabular}{|c|c|c|c|}
\hline Effect & $\begin{array}{c}\text { Both } \\
\text { routes }\end{array}$ & Infusion & Injection \\
\hline Treatment $\times$ measure & $p<0.0001$ & $p<0.0001$ & $p<0.0001$ \\
\hline Treatment $\times$ region & NS & NS & $p<0.07$ \\
\hline Treatment $\times$ measure $\times$ region & $p<0.006$ & NS & $p<0.0005$ \\
\hline Treatment $\times$ measure $\times$ route & $p<0.02$ & - & - \\
\hline Treatment $\times$ measure $\times$ age & $p<0.000$ & $p<0.0004$ & $p<0.003$ \\
\hline Treatment $\times$ region $\times$ age & NS & $p<0.06$ & NS \\
\hline Treatment $\times$ region $\times$ se $\times$ & $p<0.08$ & $p<0.02$ & NS \\
\hline Treatment $\times$ measure $\times$ region $\times$ sex & $p<0.02$ & NS & $p<0.05$ \\
\hline Treatment $\times$ measure $\times$ route $\times$ age & $p<0.03$ & - & - \\
\hline Treatment $\times$ measure $\times$ age $\times$ se $\times$ & NS & $p<0.04$ & NS \\
\hline Treatment $\times$ measure $\times$ region $\times$ se $\times$ & NS & $p<0.03$ & NS \\
\hline Treatment $\times$ route $\times$ region $\times$ age & $p<0.1$ & - & - \\
\hline Treatment $\times$ measure $\times$ region $\times$ route $\times$ age & $p<0.06$ & - & - \\
\hline Treatment $\times$ measure $\times$ region $\times$ route $\times$ se $\times$ & $p<0.06$ & - & - \\
\hline Treatment $\times$ measure $\times$ route $\times$ age $\times$ se $\times$ & $p<0.04$ & - & - \\
\hline
\end{tabular}

'Measure' refers to the three cholinergic neurochemical determinations (nAChR binding, ChAT, HC-3 binding). The main effects and interaction terms which showed no significant differences are not shown in the table. NS = not significant.

Nicotine administration via the injection route also elicited significant nAChR upregulation across the three brain regions at all doses: $p<0.0003$ at $0.6 \mathrm{mg} / \mathrm{kg} / \mathrm{day}$ and $p<0.0001$ at the two higher doses (Figure 2, right-hand panels). However, the effects were generally smaller than those seen with nicotine infusions. On PN 37, just at the end of the treatment period, the highest dose of nicotine elicited only a $15-20 \%$ increase in nAChR binding, substantially less than that seen with the infusion route. In the midbrain, the two lower doses showed no significant increase with injected nicotine. By PN65, significant elevations remained detectable in the midbrain $(p<0.008)$, but not in the cerebral cortex. In the hippocampus, values declined nearly to normal by PN45, but re-emerged by PN65 $(p<0.02)$.

Although some of the effects of nicotine on nAChRs showed sex dependence, in general, the differences were relatively minor and inconsistent. When separate determinations were made in the midbrain of males and females receiving nicotine infusions, the upregulation was significant for both (males, $p<0.0002$ for main effect, $p<0.0001$ for treatment $\times$ age; females, $p<0.0001$ for main effect, $p<0.03$ for treatment $\times$ age). In fact, the treatment $\times$ sex interaction was confined to one age (PN45, treatment $\times$ sex, $p<0.07$ ), representing an $11 \%$ bigger increase in females given $6 \mathrm{mg} / \mathrm{kg} / \mathrm{day}$, as compared to males. Similarly, in animals receiving nicotine via the injection route, effects in the midbrain were significant for both males $(p<0.002)$ and females $(p<0.0001)$ separately, with the females showing a greater overall increase in the group receiving $6 \mathrm{mg} / \mathrm{kg} / \mathrm{day}$ (average of $20 \%$ increase across all three ages, as compared to $10 \%$ increase in males). The sex differences in the cerebral cortex of the nicotine injection groups were significant overall, but were not individually significant when examined at each age point. In the hippocampus, sex differences were detected only for the nicotine infusion groups. Again, the effects were significant in both sexes, with only minor differences in the details of the time course of nAChR upregulation (not shown); on PN37, males had a bigger increase than females at $0.6 \mathrm{mg} / \mathrm{kg} / \mathrm{day}$, whereas on PN45, females had a bigger increase than males at $6 \mathrm{mg} / \mathrm{kg} /$ day.

In light of the surprisingly sensitive upregulation of nAChR binding at low doses of nicotine, we performed an additional experiment to determine both the rapidity with which receptor increases can first be detected, and the potential threshold for the effect. Using a separate cohort of animals, we administered nicotine or vehicle twice daily by subcutaneous injection for only 2 days beginning on PN30, and examined $\mathrm{nAChR}$ binding on PN32, $12 \mathrm{~h}$ after the last injection. We examined binding in the hippocampus, a region that showed significant upregulation after 1 week of injections of $0.6 \mathrm{mg} / \mathrm{kg} / \mathrm{day}$, only this time, we also examined the effects of an even lower dose, $0.2 \mathrm{mg} / \mathrm{kg} /$ day. In the control group ( 12 males, 12 females), $\mathrm{nAChR}$ binding was $35.5 \pm 0.9 \mathrm{fmol} / \mathrm{mg}$ protein, compared to $33.7 \pm 0.9$ (six males, six females) in the group receiving $0.2 \mathrm{mg} / \mathrm{kg} /$ day, and $38.9 \pm 1.5$ (six males, six females) in the $0.6 \mathrm{mg} / \mathrm{kg} / \mathrm{day}$ group. The treatment effects were significant overall $(p<0.02)$ and post hoc analysis indicated significant values in the group receiving $0.6 \mathrm{mg} / \mathrm{kg} /$ day group as compared to controls $(p<0.04)$ or to $0.2 \mathrm{mg} / \mathrm{kg} /$ day $(p<0.006)$. Upregulation thus occurred after as few as four injections (2 days of treatment), with a threshold of between 0.2 and $0.6 \mathrm{mg} / \mathrm{kg} /$ day.

Figure I Effects of adolescent nicotine administration on body and brain region weights, presented as the percent change from control values (see Table I). Nicotine was administered for I week beginning on PN30, so that the PN37 age point in each graph represents values obtained during the nicotine exposure, whereas PN45 and PN65 represent I week and I month after the end of nicotine treatment. For body weights, ANOVA indicated an interaction of nicotine treatment $\times$ route of administration, necessitating separate, lower-order tests for each route (see text). There were no significant differences in body weight for the nicotine infusion groups, but those receiving the highest dose of nicotine via injections showed significant deficits (see ANOVA in the upper right panel); separate testing for each age was not carried out because of the absence of a treatment $\times$ age interaction. For brain region weights, separate testing for each route of administration was not carried out because of the absence of an interaction of treatment $\times$ route. The main effects of nicotine across both routes were found only on PN65, representing a small overall increase in the group receiving the lowest dose of nicotine (see text); significance was not maintained when values were separated by route of administration and brain region. 

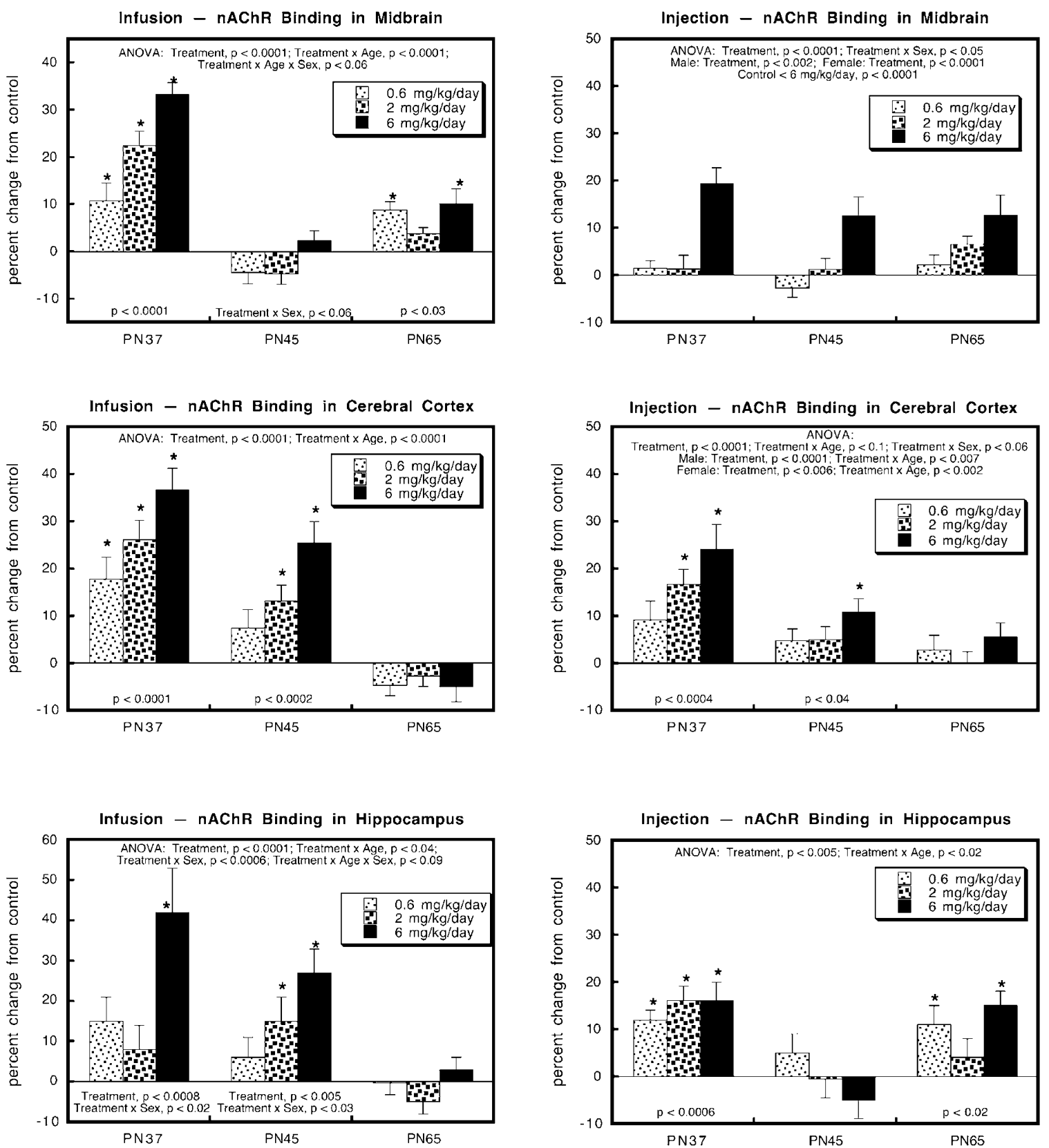

Figure 2 Effects of adolescent nicotine administration on nAChR binding, presented as the percent change from control values (see Table I). Nicotine was administered for I week beginning on PN30, so that the PN37 age point in each graph represents values obtained during the nicotine exposure, whereas PN45 and PN65 represent I week and I month after the end of nicotine treatment. ANOVA for each route and region appears at the top of each panel. Where the initial test identified an interaction of treatment $\times$ age, lower-order tests were conducted at each age, as shown at the bottom of each panel, and individual differences for each group were then assessed by Fisher's Protected Least Significant Difference (asterisks). In the absence of a treatment $\times$ age interaction, only the main effect of nicotine was reported. Sex differences in the response to nicotine are described in the text.

\section{Effects on ChAT Activity}

Across all doses, ages, regions, both routes, and both sexes, adolescent nicotine treatment elicited a significant main effect $(p<0.0002$; control $v s$ nicotine $6 \mathrm{mg} / \mathrm{kg} / \mathrm{day}, p<0.02)$ as well as interactions of treatment $\times$ region $(p<0.0001)$, treatment $\times$ route $\times$ age $\quad(p<0.08), \quad$ treatment $\times$ age $\times$ sex $(p<0.02)$, and treatment $\times$ sex $\times$ region $(p<0.09)$. Again, the data were subdivided into separate regions and routes of administration for further analysis.
Unlike the uniform increases seen for effects of adolescent nicotine on nAChRs, the effects on ChAT differed substantially among the three regions (Figure 3). In the midbrain, nicotine evoked a significant decrease in ChAT (main treatment effect, $p<0.0001$ ) that was greater for the injection route than for the infusion route (treatment $\times$ route interaction, $p<0.04)$. Considered separately, the infusion route had only a marginal effect overall, achieving significance only at the highest dose. In contrast, midbrain ChAT significantly decreased at all doses when 

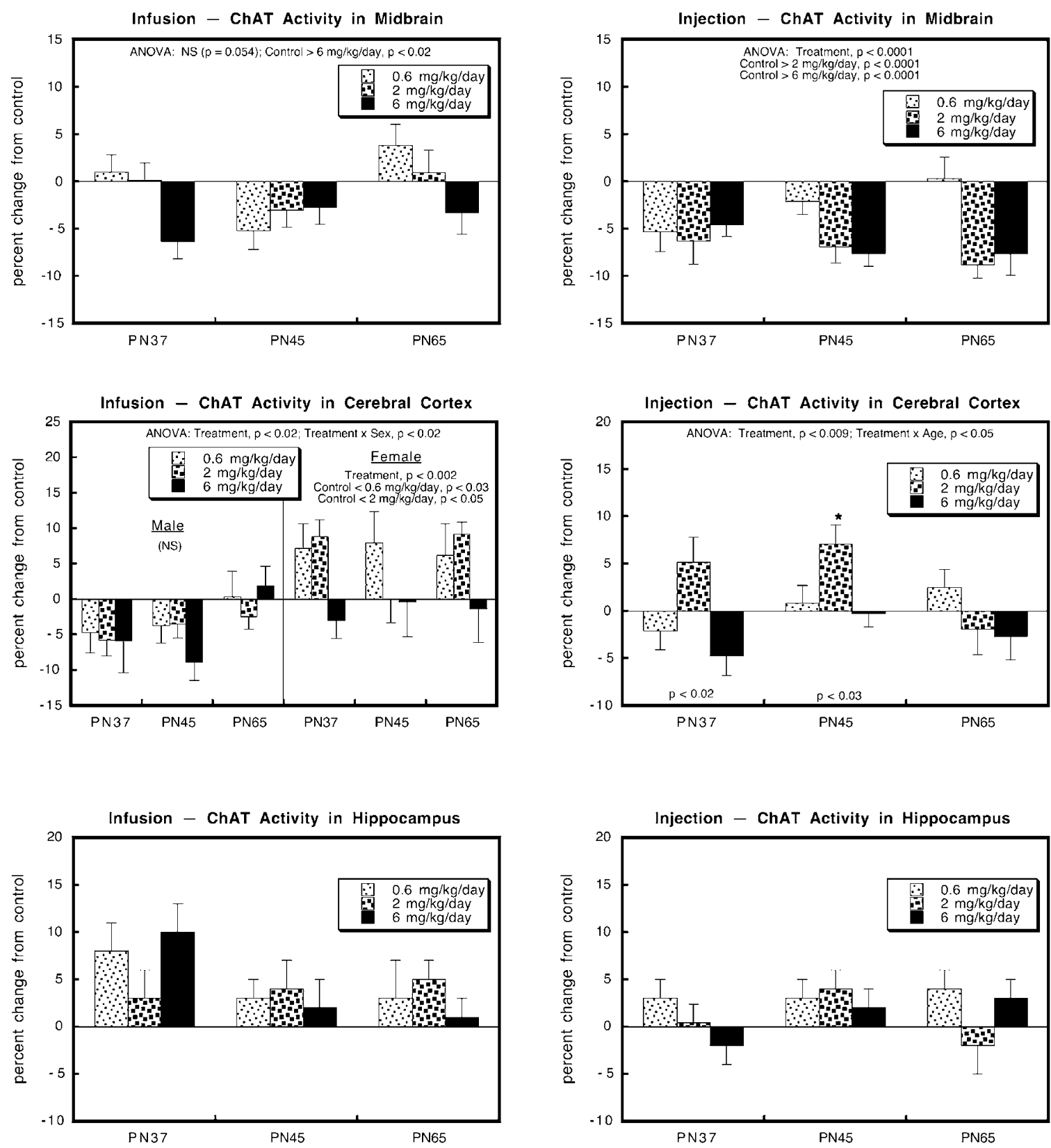

Figure 3 Effects of adolescent nicotine administration on ChAT, presented as the percent change from control values (see Table I). Nicotine was administered for I week beginning on PN30, so that the PN37 age point in each graph represents values obtained during the nicotine exposure, whereas PN45 and PN65 represent I week and I month after the end of nicotine treatment. ANOVA for each route and region appears at the top of each panel. Where the initial test identified an interaction of treatment $\times$ age, lower-order tests were conducted at each age, as shown at the bottom of each panel, and individual differences for each group were then assessed by Fisher's Protected Least Significant Difference (asterisks). In the absence of a treatment $\times$ age interaction, only the main effect of nicotine was reported. Sex differences are shown only where there was a significant treatment $\times$ sex interaction.

nicotine was given by injection, with the effect remaining prominent for the two higher doses even 1 month after discontinuing nicotine exposure. Although the cerebral cortex likewise showed a significant main effect of nicotine on ChAT $(p<0.0003)$, the response pattern was quite different, displaying distinct sex dependence (treatment $\times$ sex, $p<0.05$ ). For the infusion model, female rats showed hormesis, with promotion at the lower doses of nicotine, but a loss of the effect at $6 \mathrm{mg} / \mathrm{kg} /$ day. Males did not show any increase, and if anything, displayed lower ChAT activities. A biphasic effect on cerebrocortical ChAT was also apparent for the nicotine injection paradigm, with significant increases at $2 \mathrm{mg} / \mathrm{kg} /$ day, but not $6 \mathrm{mg} / \mathrm{kg} /$ day. In the hippocampus, analysis across both routes of administration showed a significant overall increase in ChAT: main treatment effect, $p<0.04 ; p<0.004$ for $0.6 \mathrm{mg} / \mathrm{kg} /$ day; and marginally significant at 2 or $6 \mathrm{mg} / \mathrm{kg} /$ day $(0.1>p>0.05)$ but the effect was too variable to maintain significance when either route was analyzed separately.

\section{Effects on $\left[{ }^{3} \mathrm{H}\right] \mathrm{HC}-3$ Binding}

Multivariate ANOVA incorporating all the variables indicated a highly significant main treatment effect 
$(p<0.0001)$, but no interactions of treatment with other variables. Accordingly, lower-order tests of different routes, regions, ages, and sexes were not justified. Nicotine administration elicited a decrease in HC-3 binding that was significant at all doses (Figure 4): $p<0.03$ for the groups receiving $0.6 \mathrm{mg} / \mathrm{kg} /$ day, $p<0.0001$ for those receiving $2 \mathrm{mg} /$ $\mathrm{kg} /$ day, and $p<0.0001$ for the groups receiving $6 \mathrm{mg} / \mathrm{kg} /$ day. The effect also displayed a clearcut dose-effect relation, with significant differences among all the nicotine treatment groups ( $p<0.02$ comparing 0.6 to $2 \mathrm{mg} / \mathrm{kg} /$ day, $p<0.0001$ comparing 0.6 to $6 \mathrm{mg} / \mathrm{kg} /$ day, $p<0.002$ comparing 2 to $6 \mathrm{mg} / \mathrm{kg} /$ day); collapsed across all the regions, ages, and both sexes, the effects at $2 \mathrm{mg} / \mathrm{kg} / \mathrm{day}$ were twice those obtained at $0.6 \mathrm{mg} / \mathrm{kg} /$ day, and those seen at $6 \mathrm{mg} / \mathrm{kg} /$ day were three times those of the lowest dose. Importantly, deficits in HC-3 binding remained robustly detectable on PN65 $(p<0.002$ for main treatment effect), 1 month after the termination of nicotine exposure.

\section{DISCUSSION}

Our earlier work with adolescent nicotine exposure indicated significantly greater and more persistent effects on $\mathrm{nAChR}$ upregulation and on indices of cholinergic
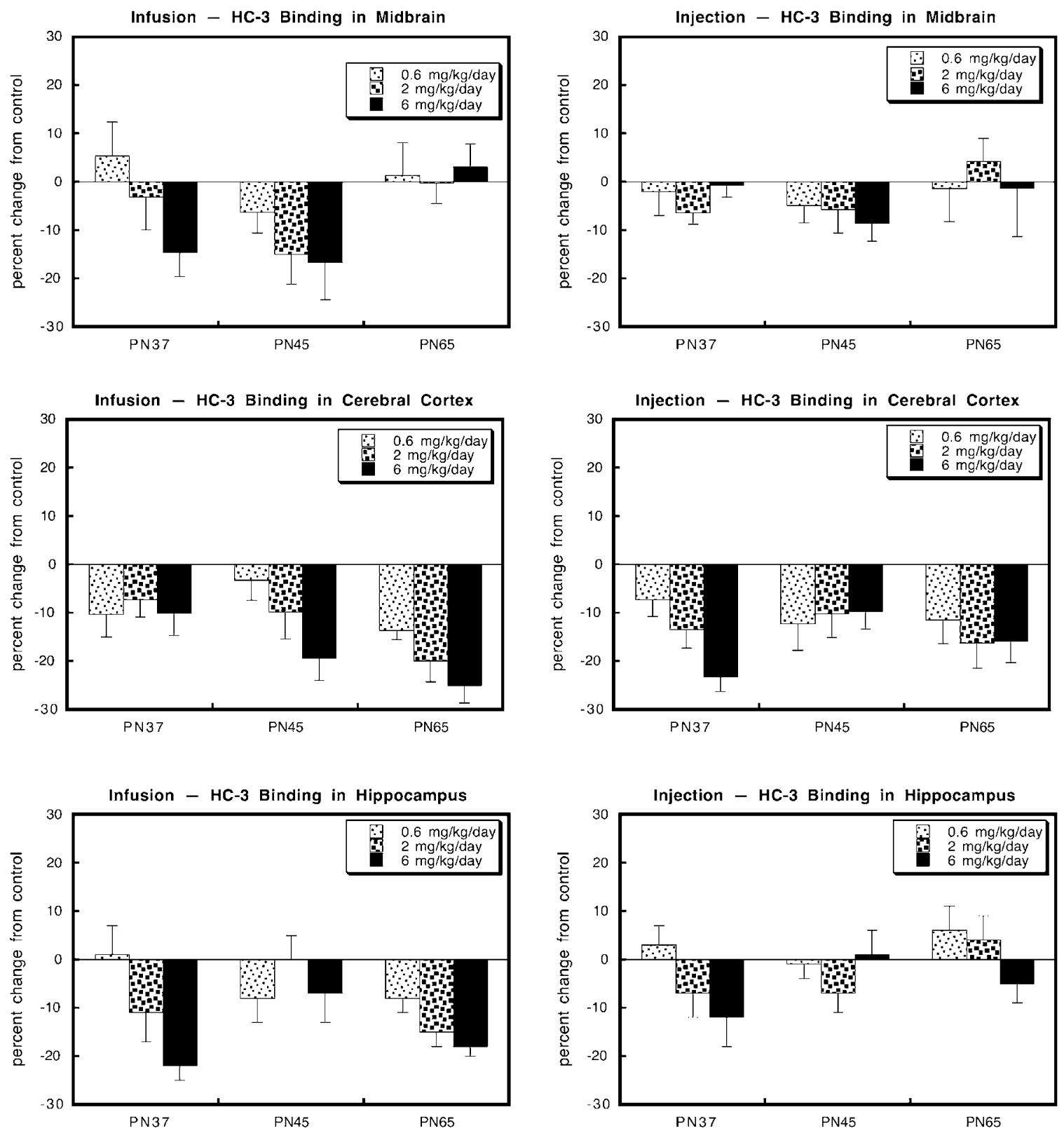

Figure 4 Effects of adolescent nicotine administration on $\left[{ }^{3} \mathrm{H}\right] \mathrm{HC}-3$ binding, presented as the percent change from control values (see Table I). Nicotine was administered for I week beginning on PN30, so that the PN37 age point in each graph represents values obtained during the nicotine exposure, whereas PN45 and PN65 represent I week and I month after the end of nicotine treatment. ANOVA was not determined for each route and region because the initial test indicated only a main treatment effect of nicotine, without interactions with other variables (see text). Effects of nicotine were significant overall $(p<0.000 \mathrm{I})$ and were distinguishable at all doses: $p<0.03$ at $0.6 \mathrm{mg} / \mathrm{kg} / \mathrm{day}$, and $p<0.000 \mathrm{I}$ at the two higher doses. 
activity than those found in adults (Happe and Murrin, 1992; Trauth et al, 1999, 2000a, 2001). Specifically, nAChR upregulation in the adolescent midbrain was twice that seen in adults and cerebrocortical values were equivalent, even when adults were exposed to nicotine at three times the plasma level; whereas persistent effects were seen 1 month post-treatment in adolescents, it was absent in adults. In the current study, we found that these changes can be elicited even with a short period of adolescent nicotine exposure (as little as 2 days to 2 week), and at a dose $(0.6 \mathrm{mg} / \mathrm{kg} /$ day $)$ that produces plasma nicotine levels only one-tenth that of typical smokers (Trauth et al, 2000b). Furthermore, we obtained evidence for persistent disruption of cholinergic function, well after the termination of nicotine treatment. Finally, continuous exposure to nicotine was not required for many of the changes: intermittent dosing via twice-daily nicotine injections was sufficient to produce nAChR upregulation and long-term alterations in biomarkers of cholinergic activity. In light of recent findings that adolescent smokers may develop signs of nicotine dependence within just a few days and with only a few cigarettes (DiFranza et al, 2000, 2002a,b), our findings provide evidence that these differences from the adult represent underlying biological differences in the adolescent brain. The ensuing paragraphs elaborate these essential conclusions in light of the specific questions fundamental to our experimental design.

\section{How Long does Nicotine Exposure Need to be in Order to Elicit Alterations in Cholinergic Activity?}

Previous studies from our group demonstrated that adolescent rats exposed to nicotine for 2 weeks showed robust, persistent nAChR upregulation, with a regional pattern distinct from that of the adult (Trauth et al, 1999). In addition, there were lasting reductions in HC-3 binding that were larger than corresponding decrements in ChAT, thus indicative of reduced cholinergic synaptic activity (Trauth et al, 2000a). In the current study, we obtained a similar pattern and magnitude of nAChR upregulation with only 1 week of nicotine exposure, and in an additional experiment, with as little as 2 days' treatment. As before, in addition to these immediate effects, there were persistent effects on nAChRs, as well as long-lasting suppression of HC-3 binding, for up to 1 month post-treatment. Reductions in HC-3 binding could conceivably involve either loss of cholinergic synaptic terminals, or reductions in neuronal impulse activity. However, if the terminals were reduced, then ChAT activity would have shown the same reduction as did HC-3 binding. The fact that there was preferential loss of the activity-related marker, HC-3 binding, indicates that the effects represent a long-term reduction in cholinergic tone. Our results thus indicate that even a brief period of nicotine exposure in early adolescence is sufficient to cause global changes to both nAChRs and cholinergic activity. Notably, the nAChR ligand we used, $\left[{ }^{3} \mathrm{H}\right]$ cytisine, binds to the $\alpha 4 \beta 2$ receptor, the most widely distributed subtype in the brain (Buisson and Bertrand, 2002). Upregulation of $\alpha 4 \beta 2 \mathrm{nAChRs}$ is thought to be initiated by receptor desensitization (Fenster et al, 1999) and both desensitization and upregulation are hypothesized to play a role in addiction mechanisms (Buisson and Bertrand, 2001, 2002; Dani and De Biasi, 2001; Quick and Lester, 2002).

It is also notable that the pattern of persistent changes in biomarkers of cholinergic synaptic function seen here resemble those reported previously for prenatal nicotine exposure (Zahalka et al, 1992), which similarly evoked deficits in HC-3 binding independent of any comparable changes in ChAT. Our results indicate that the critical period in which nicotine can disrupt the programming of cholinergic function thus extends from fetal through adolescent stages. Furthermore, with the adolescent exposure paradigm, we found emergence of the deficits in HC3 binding, hence reduced cholinergic synaptic activity, during the nicotine treatment period. Accordingly, the persistence of this effect 1 month post-treatment is not likely to reflect nicotine withdrawal, but rather a persistent effect of nicotine on the programming of cholinergic tone.

\section{What is the Dose Threshold for these Effects?}

Adolescent rats given infusions of $6 \mathrm{mg} / \mathrm{kg} /$ day of nicotine, display plasma nicotine levels comparable to those in typical smokers $(25 \mathrm{ng} / \mathrm{ml})$ (Trauth et al, 2000b). In order to determine whether similar effects could be elicited at much lower plasma nicotine concentrations, we reduced the dose to 2 or $0.6 \mathrm{mg} / \mathrm{kg} / \mathrm{day}$. Since the relation between dose and plasma levels is linear (Lichtensteiger et al, 1988), these regimens correspond to approximately 8 and $2.5 \mathrm{ng} / \mathrm{ml}$, respectively; the lowest concentration produces a plasma level projected to be 10 times lower than that found in regular smokers. For nAChR upregulation, we found significant increases and the same persistence at all dose levels. Similarly, the long-lasting decrements in HC-3 binding remained detectable at all doses. Thus, the receptor changes that are thought to underlie nicotine dependence, as well as the persistent reductions in cholinergic synaptic activity, are both prominent features at exposure levels well below those of typical smokers. Indeed, the levels studied here encompass the so-called 'chippers,' who smoke up to five cigarettes per day and have nicotine plasma levels $20 \%$ those of regular smokers (Shiffman et al, 1990), as well as those with regular exposure to ETS, typically one-tenth those of active smokers (Eliopoulos et al, 1996; Eskenazi and Bergmann, 1995; Fried et al, 1995; Jauniaux et al, 1999; Kohler et al, 1999; Ostrea et al, 1994), but ranging up to levels indistinguishable from those in active, light smokers (Koren et al, 1998). Our findings thus raise the possibility that, in the adolescent brain, the biological mechanisms underlying nicotine dependence can be activated by nicotine exposures comparable to occasional smoking or even ETS exposure.

\section{Does the Pattern of Exposure Matter?}

Whereas our earlier work with the adolescent nicotine model concentrated on the effects of continuous, steadystate exposure to nicotine via continuous infusions (for a review see Slotkin, 2002), in the present work we compared nicotine infusions to the same daily doses delivered intermittently by twice-daily injections. This issue is particularly important in trying to understand the mechanisms that might underlie the onset of dependence in 
adolescent humans who smoke only a few cigarettes (DiFranza et al, 2000, 2002a, b). Both treatment paradigms elicited nAChR upregulation across all three dose levels, although in general, the effect was greater with nicotine infusions. This difference was not unexpected, given the greater likelihood of $\mathrm{nAChR}$ desensitization with continuous exposure (Fenster et al, 1999), as intermittent exposure allows for some recovery in between doses. Nevertheless, significant nAChR upregulation was indeed found even with the lowest dose of injected nicotine, corresponding (after correction for interspecies differences) to a net consumption of as little as two cigarettes per day (Lichtensteiger et al, 1988; Trauth et al, 2000b); this fact, combined with the observation that the effects appear after as few as four injections (two days' exposure) reinforces the exquisite sensitivity of the adolescent brain to nicotine. Similarly, the long-term suppression of cholinergic synaptic activity, as indicated by reduced HC-3 binding, was fully evident with the injection paradigm. Again, our findings in adolescent rat brain thus provide evidence for biological mechanisms that are likely to underlie the emergence of nicotine dependence in adolescents within days after initiation of occasional tobacco use (DiFranza et al, 2000, 2002a, b).

\section{What is the Role of Secondary Effects of Nicotine?}

As detailed in the methods section, in contrast to rats that received nicotine infusions, rats that received the highest dose of injected nicotine exhibited clearcut signs of systemic toxicity, such as blanching of the skin and cyanosis (McFarland et al, 1991; Slotkin, 1992), as well as body weight deficits. Accordingly, the fact that nAChR upregulation and decrements in HC-3 binding were shared by both administration paradigms, involved doses below the threshold for systemic toxicity, and tended to be larger in animals receiving the infusions, all suggest that secondary toxic effects are not major contributors to these components of the effects of adolescent nicotine.

\section{Is Nicotine a Neurotoxin in the Adolescent Brain?}

The general conclusion that systemic toxicity of nicotine does not account for effects on the adolescent brain, leaves open the possibility of primary neurotoxicity of nicotine that may occur independent of systemic actions. Indeed, with fetal exposure, nicotine elicits specific, receptormediated effects on cell replication, differentiation, and synaptogenesis that contribute to its neurobehavioral teratogenicity (Levin and Slotkin, 1998; Slotkin, 1992, 1998, 1999), and at least some of these mechanisms persist into adolescence (Slotkin, 2002). Although direct evidence for adolescent brain cell injury caused by low-dose nicotine exposure is being pursued in a separate study (AbreuVillaça et al, 2003), the current results for ChAT provide some evidence of neurotoxicant actions. ChAT is a constitutive cholinergic synaptic biomarker, so that its activity largely reflects the density of cholinergic innervation (Aubert et al, 1996; Happe and Murrin, 1992; Navarro et al, 1989; Slotkin et al, 1990; Zahalka et al, 1992, 1993). In our earlier work with a 2 -week infusion of $6 \mathrm{mg} / \mathrm{kg} /$ day of nicotine, we found small, but statistically significant decrements in ChAT (Trauth et al, 2000a) that corresponded to loss of neural cells (Trauth et al, 2000b). The current study again indicates that, in at least one region (midbrain), a 1-week regimen is sufficient to elicit the effect on ChAT. Notably, however, we obtained a more robust effect with nicotine injections, which produced deficits in ChAT even at the lowest dose. These differences between the two routes were not shared by the biomarker of cholinergic synaptic activity, HC-3 binding, which instead showed decrements across all brain regions and, if anything, greater midbrain effects for the infusion paradigm. Accordingly, the degree of synaptic damage may differ between the two administration paradigms; direct assessments of this possibility.

The pattern of nicotine-induced changes in ChAT was highly region-specific. Whereas decreases were seen in the midbrain, values in the cerebral cortex and hippocampus tended instead to be elevated. Even more intriguing, the promotional effect on ChAT in the latter two regions was not a monotonic function of dose, but rather displayed hormesis, with reversal of the effect at higher doses, a typical finding for other aspects of nicotine's biological effects (Furst, 1987). In fact, the biphasic effects on ChAT might be expected from the fact that the activation of nAChRs serves a trophic role in neurodevelopment (Coronas et al, 2000; Hohmann and Berger-Sweeney, 1998; Hohmann et al, 1988; Navarro et al, 1989; Pugh and Margiotta, 2000), while at the same time, excessive stimulation disrupts patterns of cell replication, differentiation, and synaptogenesis (Levin and Slotkin, 1998; Slotkin, 1992, 1998, 1999), progressing at high levels to outright cell damage (Abrous et al, 2002; Slotkin, 1992, 1998; Trauth et al, $2000 \mathrm{~b})$. The fact that neuronal cell replication continues into adolescence in late-developing regions may render these particular areas especially vulnerable to hormetic effects of nicotine (Altman and Bayer, 1990; McWilliams and Lynch, 1983; Zahalka et al, 1992, 1993). Alternatively, the elevations in ChAT may represent sprouting as a compensatory response to decrements in cholinergic synaptic function, although it would then be expected that the midbrain should show the same pattern. Obviously, the current results do not address the specific mechanism(s) for the hormetic response of ChAT to adolescent nicotine administration, and future studies will need to address the anatomical features that underlie the neurochemical changes, and perhaps more importantly, whether there is a parallel, biphasic effect on behavioral parameters.

Tobacco use by adolescents is a worldwide public health issue of widening severity, and the resultant rise in the number of life-long smokers will place an increasing burden on health care resources and on society in general. Nicotine dependence can be discerned in adolescents who smoke even occasionally (DiFranza et al, 2000, 2002a, b), so that this developmental period is a crucial component of the commencement of lifetime smoking. The present results indicate immediate and persistent alterations in nAChRs and cholinergic function in the adolescent rat brain even at nicotine doses one-tenth of those found in regular smokers, even with only intermittent dosing. Accordingly, our findings support the concept that the onset of nicotine dependence in the adolescent represents, in part, basic 
differences in the biological responses to nicotine that are unique to this period of brain development.

\section{ACKNOWLEDGEMENTS}

This work was supported by a grant and fellowship from the External Research Program of Philip Morris, USA, Inc., and by a fellowship from CNPq Brazil.

\section{REFERENCES}

Abreu-Villaça Y, Scidler FJ, Tate CA, Slotkin TA (2003). Nicotine is a neurotoxin in the adolescent brain: critical periods, patterns of exposure, regional selectivity, and dose thresholds for macromolecular alterations. Brain Res, in press.

Abrous DN, Adriani W, Montaron MF, Aurousseau C, Rougon G, Le Moal $\mathrm{M}$ et al (2002). Nicotine self-administration impairs hippocampal plasticity. J Neurosci 22: 3656-3662.

Adriani W, Macri S, Pacifici R, Laviola G (2002). Peculiar vulnerability to nicotine oral self-administration in mice during early adolescence. Neuropsychopharmacology 27: 212-224.

Altman J, Bayer SA (1990). Migration and distribution of two populations of hippocampal granule cell precursors during the perinatal and postnatal periods. J Comp Neurol 301: 365-381.

Aubert I, Cecyre D, Gauthier S, Quirion R (1996). Comparative ontogenic profile of cholinergic markers, including nicotinic and muscarinic receptors, in the rat brain. J Comp Neurol 369: 31-55.

Bayer SA (1983). $\left[{ }^{3} \mathrm{H}\right]$ Thymidine-radiographic studies of neurogenesis in the rat olfactory bulb. Exp Brain Res 50: 329-340.

Bayer SA, Yackel JW, Puri PS (1982). Neurons in the rat dentate gyrus granular layer substantially increase during juvenile and adult life. Science 216: 890-892.

Buisson B, Bertrand D (2001). Chronic exposure to nicotine upregulates the human $\alpha 4 \beta 2$ nicotinic acetylcholine receptor function. J Neurosci 21: 1819-1829.

Buisson B, Bertrand D (2002). Nicotine addiction: the possible role of functional upregulation. Trends Pharmacol Sci 23: 130-136.

Bush PG, Mayhew TM, Abramovich DR, Aggett PJ, Burke MD, Page KR (2000). Maternal cigarette smoking and oxygen diffusion across the placenta. Placenta 21: 824-833.

Centers for Disease Control Prevention (1998). Tobacco use among high school students-United States, 1997. Morbid Mortal Weekly Rep 47: 229-233.

Centers for Disease Control and Prevention (2000). Trends in cigarette smoking among high school students: United States, 1991-1999. Morbid Mortal Weekly Rep 49: 755-758.

Chen J, Millar WJ (1998). Age of smoking inititation: implications for quitting. Health Rep 9: 39-46.

Cheney DL, Lehmann J, Cosi C, Wood PL (1989). Determination of acetylcholine dynamics. Drugs Tools Neurotransm Res 12: 443-495.

Cirulli F, Laviola G (2000). Paradoxical effects of D-amphetamine in infant and adolescent mice: role of gender and environmental risk factors. Neurosci Biobehav Rev 24: 73-84.

Coronas V, Durand M, Chabot JG, Jourdan F, Quirion R (2000). Acetylcholine induces neuritic outgrowth in rat primary olfactory bulb cultures. Neuroscience 98: 213-219.

Dani JA, De Biasi M (2001). Cellular mechanisms of nicotine addiction. Pharmacol Biochem Behav 70: 439-446.

DiFranza J, Savageau JA, Rigotti NA, Fletcher K, Ockene JK, $\mathrm{McNeill} \mathrm{AD} \mathrm{et} \mathrm{al} \mathrm{(2002a).} \mathrm{Development} \mathrm{of} \mathrm{symptoms} \mathrm{of} \mathrm{tobacco}$ dependence in youths: 30-month follow-up data from the DANDY study. Tobacco Control 11: 228-235.

DiFranza JR, Rigotti NA, McNeill AD, Ockene JK, Savageau JA, St. Cyr D et al (2000). Initial symptoms of nicotine dependence in adolescents. Tobacco Contr 9: 313-319.
DiFranza JR, Savageau JA, Fletcher K, Ockene JK, Rigotti NA, McNeill AD et al (2002b). Measuring the loss of autonomy over nicotine use in adolescents: the DANDY (development and assessment of nicotine dependence in youths) study. Arch Pediatr Adolesc Med 156: 397-403.

Eliopoulos C, Klein J, Chitayat D, Greenwald M, Koren G (1996). Nicotine and cotinine in maternal and neonatal hair as markers of gestational smoking. Clin Invest Med 19: 231-242.

Eskenazi B, Bergmann JJ (1995). Passive and active maternal smoking during pregnancy, as measured by serum cotinine, and postnatal smoke exposure. 1. Effects on physical growth at age 5 years. Am J Epidemiol 142: S10-S18.

Faraday MM, Elliott BM, Grunberg NE (2001). Adult vs adolescent rats differ in biobehavioral responses to chronic nicotine administration. Pharmacol Biochem Behav 70: 475-489.

Fenster CP, Whitworth TL, Sheffield EB, Quick MW, Lester RAJ (1999). Upregulation of surface $\alpha_{4} \beta_{2}$ nicotinic receptors is initiated by receptor desensitization after chronic exposure to nicotine. J Neurosci 19: 4804-4814.

Flores CM, Rogers SW, Pabreza LA, Wolfe BB, Kellar KJ (1992). A subtype of nicotinic cholinergic receptor in rat brain is composed of $\alpha 4$ and $\beta 2$ subunits and is upregulated by chronic nicotine treatment. Mol Pharmacol 41: 31-37.

Fried PA, Perkins SL, Watkinson B, McCartney JS (1995). Association between creatinine-adjusted and unadjusted urine cotinine values in children and the mother's report of exposure to environmental tobacco smoke. Clin Biochem 28: $415-420$.

Furst A (1987). Hormetic effects in pharmacology: pharmacological inversions as prototypes for hormesis. Health Phys 52: 527-530.

Happe HK, Murrin LC (1992). High-affinity choline transport regulation by drug administration during postnatal development. J Neurochem 58: 2053-2059.

Happe HK, Peters JL, Bergman DA, Murrin LC (1994). Localization of nicotinic cholinergic receptors in rat brain: autoradiographic studies with $\left[{ }^{3} \mathrm{H}\right]$ cytisine. Neuroscience 62: 929-944.

Hohmann CF, Berger-Sweeney J (1998). Cholinergic regulation of cortical development and plasticity: new twists to an old story. Perspect Dev Neurobiol 5: 401-425.

Hohmann CF, Brooks AR, Coyle JT (1988). Neonatal lesions of the basal forebrain cholinergic neurons result in abnormal cortical development. Dev Brain Res 42: 253-264.

Huttenlocher PR (1990). Morphometric study of human cerebral cortex development. Neuropsychologia 28: 517-527.

Jackson C (1998). Cognitive susceptibility to smoking and initiation of smoking during childhood: a longitudinal study. Prev Med 27: 129-134.

Jauniaux E, Gulbis B, Acharya G, Thiry P, Rodeck C (1999). Maternal tobacco exposure and cotinine levels in fetal fluids in the first half of pregnancy. Obstet Gynecol 83: 25-29.

Jope RS (1979). High affinity choline transport and acetylCoA production in brain and their roles in the regulation of acetylcholine synthesis. Brain Res Rev 1: 314-344.

Kelley BM, Middaugh LD (1999). Periadolescent nicotine exposure reduces cocaine reward in adult mice. J Addict Dis 18: $27-39$.

Klemm N, Kuhar MJ (1979). Post-mortem changes in high affinity choline uptake. J Neurochem 32: 1487-1494.

Kohler E, Sollich V, Schuster R, Thal W (1999). Passive smoke exposure in infants and children with respiratory tract diseases. Human Exp Toxicol 18: 212-217.

Koren G, Eliopoulos C, Klein J (1998). Measuring fetal exposure to nicotine. In: Benowitz NL (eds) Nicotine Safety and Toxicity. Oxford University Press: New York. pp 99-106.

Lamkin LP, Houston TP (1998). Nicotine dependency and adolescents: preventing and treating. Prim Care 25: 123-135. 
Lau C, Seidler FJ, Cameron AM, Navarro HA, Bell JM, Bartolome J et al (1988). Nutritional influences on adrenal chromaffin cell development: comparison with central neurons. Pediatr Res 24: 583-587.

Leventhal H, Cleary PD (1980). The smoking problem: a review of the research and theory in behavioral risk modification. Psychol Bull 88: 370-405.

Levin ED (1999). Persisting effects of chronic adolescent nicotine administration on radial-arm maze learning and response to nicotinic challenges. Neurotoxicol Teratol 21: 338.

Levin ED, Slotkin TA (1998). Developmental neurotoxicity of nicotine. In: Slikker W, Chang LW (eds) Handbook of Developmental Neurotoxicology. Academic Press: San Diego. pp 587-615.

Lichtensteiger W, Ribary U, Schlumpf M, Odermatt B, Widmer HR (1988). Prenatal adverse effects of nicotine on the developing brain. Prog Brain Res 73: 137-157.

Markwiese BJ, Acheson SK, Levin ED, Wilson WA, Swartzwelder HS (1998). Differential effects of ethanol on memory in adolescent and adult rats. Alcohol Clin Exp Res 22: 416-421.

Matthews DA, Nadler JV, Lynch GS, Cotman CW (1974). Development of cholinergic innervation in the hippocampal formation of the rat. Dev Biol 36: 130-141.

McFarland BJ, Seidler FJ, Slotkin TA (1991). Inhibition of DNA synthesis in neonatal rat brain regions caused by acute nicotine administration. Dev Brain Res 58: 223-229.

McWilliams JR, Lynch G (1983). Rate of synaptic replacement in denervated rat hippocampus declines precipitously from the juvenile period to adulthood. Science 221: 572-574.

Murray CJL, Lopez AD (1997). Alternative projections of mortality and disability by cause 1990-2020: global burden of disease study. Lancet 349: 1498-1504.

Murrin LC (1980). High-affinity transport of choline in neuronal tissue. Pharmacology 21: 132-140.

Nadler JV, Matthews DA, Cotman CW, Lynch GS (1974). Development of cholinergic innervation in the hippocampal formation of the rat. II. Quantitative changes in choline acetyltransferase and acetylcholinesterase activities. Dev Biol 36: 142-154.

National Institute on Drug Abuse (1998). Nicotine addiction. NIH Publication Number 98-4342, Washington, DC, 7pp.

Navarro HA, Basta PV, Seidler FJ, Slotkin TA (2003). Short-term adolescent nicotine exposure in rats elicits immediate and delayed deficits in T-lymphocyte function: critical periods, patterns of exposure, dose thresholds. Nicotine Tobacco Res, in press.

Navarro HA, Seidler FJ, Eylers JP, Baker FE, Dobbins SS, Lappi SE et al (1989). Effects of prenatal nicotine exposure on development of central and peripheral cholinergic neurotransmitter systems. Evidence for cholinergic trophic influences in developing brain.. J Pharmacol Exp Ther 251: 894-900.

Nelson DE, Giovino GA, Shopland DR, Mowery PD, Mills SL, Eriksen MP (1995). Trends in cigarette smoking among US adolescents, 1974 through 1991. Am J Public Health 85: 34-40.

O'Loughlin J, Kishchuk N, DiFranza J, Tremblay M, Paradis G (2002). The hardest thing is the habit: a qualitative investigation of adolescent smokers' experience of nicotine dependence. Nicotine Tobacco Res 4: 201-209.

Ostrea EM, Knapp DK, Romero A, Montes M, Ostrea AR (1994). Meconium analysis to assess fetal exposure to nicotine by active and passive maternal smoking. J Pediatrics 124: 471-476.

Pierce JP, Gilpin E (1996). How long will today's new adolescent smoker be addicted to cigarettes? Am J Pub Health 86: 253-256.

Pugh PC, Margiotta JF (2000). Nicotinic acetylcholine receptor agonists promote survival and reduce apoptosis of chick ciliary ganglion neurons. Mol Cell Neurosci 15: 113-122.
Quick MW, Lester RA (2002). Desensitization of neuronal nicotinic receptors. J Neurobiol 53: 457-478.

Shelton DL, Nadler JV, Cotman CW (1979). Development of high affinity choline uptake and associated acetylcholine synthesis in the rat fascia dentata. Brain Res 163: 263-275.

Shiffman S, Fischer LB, Zettler-Segal M, Benowitz NL (1990). Nicotine exposure among nondependent smokers. Arch Gen Psychiatry 47: 333-336.

Simon JR, Atweh S, Kuhar MJ (1976). Sodium-dependent high affinity choline uptake: a regulatory step in the synthesis of acetylcholine. J Neurochem 26: 909-922.

Slawecki CJ, Ehlers CL (2002). Lasting effects of adolescent nicotine exposure on the electroencephalogram, event related potentials, and locomotor activity in the rat. Dev Brain Res 138 15-25.

Slotkin TA (1992). Prenatal exposure to nicotine: what can we learn from animal models?. In: Zagon IS, Slotkin TA (eds) Maternal Substance Abuse and the Developing Nervous System. Academic Press: San Diego. pp 97-124.

Slotkin TA (1998). Fetal nicotine or cocaine exposure: which one is worse? J Pharmacol Exp Ther 285: 931-945.

Slotkin TA (1999). Developmental cholinotoxicants: nicotine and chlorpyrifos. Environ Health Perspect 107(Suppl 1): 71-80.

Slotkin TA (2002). Nicotine and the adolescent brain: insights from an animal model. Neurotoxicol Teratol 24: 369-384.

Slotkin TA, Seidler FJ, Crain BJ, Bell JM, Bissette G, Nemeroff CB (1990). Regulatory changes in presynaptic cholinergic function assessed in rapid autopsy material from patients with Alzheimer disease: implications for etiology and therapy. Proc Natl Acad Sci USA 87: 2452-2455.

Smith PK, Krohn RI, Hermanson GT, Mallia AK, Gartner FH, Provenzano MD et al (1985). Measurement of protein using bicinchoninic acid. Anal Biochem 150: 76-85.

Snedecor GW, Cochran WG (1967). Statistical Methods. Iowa State University Press: Ames, IA. pp 346-349.

Spear LP (2000). The adolescent brain and age-related behavioral manifestations. Neurosci Biobehav Rev 24: 417-463.

Spear LP, Brake SC (1983). Periadolescence: age-dependent behavior and psychopharmacological responsivity in rats. Dev Psychobiol 16: 83-109.

Trauth JA, McCook EC, Seidler FJ, Slotkin TA (2000a). Modeling adolescent nicotine exposure: effects on cholinergic systems in rat brain regions. Brain Res 873: 18-25.

Trauth JA, Seidler FJ, Ali SF, Slotkin TA (2001). Adolescent nicotine exposure produces immediate and long-term changes in CNS noradrenergic and dopaminergic function. Brain Res $\mathbf{8 9 2}$ 269-280.

Trauth JA, Seidler FJ, McCook EC, Slotkin TA (1999). Adolescent nicotine exposure causes persistent upregulation of nicotinic cholinergic receptors in rat brain regions. Brain Res 851: 9-19.

Trauth JA, Seidler FJ, Slotkin TA (2000b). An animal model of adolescent nicotine exposure: effects on gene expression and macromolecular constituents in rat brain regions. Brain Res 867: 29-39.

Trauth JA, Seidler FJ, Slotkin TA (2000c). Persistent and delayed behavioral changes after nicotine treatment in adolescent rats. Brain Res 880: 167-172.

Vickroy T, Roeske W, Yamamura H (1984). Sodium-dependent high-affinity binding of $[3 \mathrm{H}]$ hemicholinium- 3 in the rat brain: a potentially selective marker for presynaptic cholinergic sites. Life Sci 35: 2335-2343.

Whiting P, Lindstrom J (1987). Purification and characterization of a nicotinic acetylcholine receptor from rat brain. Proc Natl Acad Sci 84: 595-599.

Whiting PR, Lindstrom J (1988). Characterization of bovine and human neuronal nicotinic acetylcholine receptors using monoclonal antibodies. J Neurosci 8: 3395-3404. 
Zahalka E, Seidler FJ, Lappi SE, Yanai J, Slotkin TA (1993). Differential development of cholinergic nerve terminal markers in rat brain regions: Implications for nerve terminal density, impulse activity and specific gene expression. Brain Res 601: 221-229.
Zahalka EA, Seidler FJ, Lappi SE, McCook EC, Yanai J, Slotkin TA (1992). Deficits in development of central cholinergic pathways caused by fetal nicotine exposure: differential effects on choline acetyltransferase activity and $\left[{ }^{3} \mathrm{H}\right]$ hemicholinium-3 binding. Neurotoxicol Teratol 14: 375-382. 